OPEN ACCESS

Edited by:

Paul W. Bland,

University of Gothenburg, Sweden

Reviewed by:

Siegfried Hapfelmeier,

Universität Bern, Switzerland

Sukanya Raghavan,

University of Gothenburg, Sweden

*Correspondence:

Mitchell H. Grayson

wheeze@allergist.com

tPresent address:

Lauren E. Camarda,

Advocate Children's Hospital,

Park Ridge, IL, United States;

Dorothy S. Cheung,

Genentech, South San Francisco,

CA, United States

*These authors have contributed equally to this work.

Specialty section:

This article was submitted

to Mucosal Immunity,

a section of the journal

Frontiers in Immunology

Received: 13 March 2018 Accepted: 26 June 2018

Published: 10 July 2018

Citation:

Grayson MH, Camarda LE,

Hussain S-RA, Zemple SJ,

Hayward M, Lam V, Hunter DA,

Santoro JL, Rohlfing M, Cheung DS

and Salzman NH (2018) Intestinal

Microbiota Disruption Reduces

Regulatory T Cells and Increases

Respiratory Viral Infection Mortality

Through Increased IFNy Production.

Front. Immunol. 9:1587.

doi: 10.3389/fimmu.2018.01587

\section{Intestinal Microbiota Disruption Reduces Regulatory T Cells and Increases Respiratory Viral Infection Mortality Through Increased IFN $\gamma$ Production}

\author{
Mitchell H. Grayson ${ }^{1,2 * \neq}$, Lauren E. Camarda ${ }^{1,3+}$, Syed-Rehan A. Hussain ${ }^{2}$, \\ Sarah J. Zemple', Michael Hayward ${ }^{4}$, Vy Lam ${ }^{4}$, Desiré A. Hunter ${ }^{1}$, Jennifer L. Santoro ${ }^{1,2}$, \\ Michelle Rohlfing ${ }^{1,2}$, Dorothy S. Cheung ${ }^{1+}$ and Nita H. Salzman ${ }^{4 \neq}$
}

'Division of Allergy and Clinical Immunology, Medical College of Wisconsin, Milwaukee, WI, United States, ${ }^{2}$ Division of Allergy and Immunology, Nationwide Children's Hospital and The Ohio State University, Columbus, $\mathrm{OH}$, United States, ${ }^{3}$ Division of Pulmonary and Sleep Medicine, Medical College of Wisconsin, Milwaukee, WI, United States, ${ }^{4}$ Division of Gastroenterology, Department of Pediatrics, Medical College of Wisconsin, Milwaukee, WI, United States

Alterations in gastrointestinal microbiota indirectly modulate the risk of atopic disease, but effects on respiratory viral infections are less clear. Using the murine paramyxoviral virus type 1, Sendai virus (SeV), we examined the effect of altering gastrointestinal microbiota on the pulmonary antiviral immune response. C57BL6 mice were treated with streptomycin before or during infection with $\mathrm{SeV}$ and resulting immune response studied. Ingestion of the non-absorbable antibiotic streptomycin led to a marked reduction in intestinal microbial diversity without a significant effect on lung microbiota. Reduction in diversity in the gastrointestinal tract was followed by greatly increased mortality to respiratory viral infection $(p<0.0001)$. This increase in mortality was associated with a dysregulated immune response characterized by decreased lung $(p=0.01)$ and intestinal $(p=0.03)$ regulatory T cells (Tregs), and increased lung IFNr $(p=0.049)$, IL-6 $(p=0.015)$, and CCL2 $(p=0.037)$. Adoptive transfer of Treg cells or neutralization of IFN $\gamma$ prevented increased mortality. Furthermore, $\mathrm{Lin}^{-} \mathrm{CD} 4^{+}$cells appeared to be a potential source of the increased IFN $\gamma$. Together, these results demonstrate gastrointestinal microbiota modulate immune responses at distant mucosal sites and have the ability to significantly impact mortality in response to a respiratory viral infection.

Keywords: virus, respiratory infection, gastrointestinal microbiome, pulmonary immune response, pulmonary microbiome, innate lymphoid cells

\section{INTRODUCTION}

The intestinal microbiome plays essential roles in host physiology, nutrition, immune development, and protection (1). Specific members of this complex ecosystem have been implicated in the development of both pro-inflammatory (2-6) and regulatory $(3,7-9)$ immune responses. In genetically susceptible mice, there is evidence that the intestinal microbiota drive development of colitis $(7,9,10)$, type 1 diabetes $(11)$, obesity (12), autoimmune arthritis (6), and experimental autoimmune encephalomyelitis (5). The mechanisms by which the microbiota influence these disease processes 
are complex and not entirely clear. In humans, the microbiota are directly associated with diseases such as inflammatory bowel disease and necrotizing enterocolitis $(13,14)$. More indirect relationship studies have suggested that the intestinal microbiota may play a role in modulating the risk for many other clinical diseases including asthma and allergic disease (15-18).

Antibiotic use causes significant and persistent disruption of the intestinal microbial ecosystem $(19,20)$. This disruption has been associated with increased susceptibility to intestinal infection. In mice, pretreatment with antibiotics is a common approach used to study infection by diverse enteric pathogens, including Salmonella enterica (21), Enterococcus faecalis (22), and E. coli (23). These observations support the concept that an intact microbiota provides colonization resistance to enteric pathogens. In humans, there is similar evidence of antibiotic-associated intestinal infections, such as Clostridium difficile $(24,25)$ and E. faecalis (26), normally held in check by an intact microbiota, and successfully treated by reconstitution of the intestinal microbiota with fecal transplantation $(27,28)$. While it is clear that antibiotic modulation of the intestinal microbial ecosystem alters the immune system in the gastrointestinal tract, evidence suggests that disrupting the intestinal microbiota alters immune responses at distant mucosal and non-mucosal sites $(5,6,29,30)$.

One distant mucosal site to the intestine is the respiratory tract. We undertook this study to see how alterations in the intestinal microbiota might affect the immune response to a natural rodent respiratory viral pathogen, Sendai virus $(\mathrm{SeV})$. The mouse parainfluenza virus type $1, \mathrm{SeV}$, is a rodent pathogen of the paramyxoviridae family [same family as respiratory syncytial virus (RSV) and human parainfluenza viruses 1-3]. Our studies and others have well characterized the antiviral immune response to $\mathrm{SeV}$ (31-34). C57BL6 mice infected with the appropriate inoculum lose nearly $20 \%$ of their body weight over 10 days, and clear the virus around day $10-12$ post inoculation (PI). Fewer than $5 \%$ of infected wild-type mice die of the infection, and those that survive are left with mucous cell metaplasia that is dependent on IgE and the high-affinity receptor for IgE, FceRI, on lung dendritic cells $(31,33)$. Using $\mathrm{SeV}$, we sought to determine if alteration of the intestinal microbiota by a non-absorbed antibiotic would lead to changes in the respiratory immune response against a wellcharacterized respiratory viral infection.

\section{MATERIALS AND METHODS}

\section{Mouse Handling and SeV Inoculation}

C57BL/6, Cd8 $8^{-/-}$, and Foxp3 $3 f p$ male mice were obtained from The Jackson Laboratory (Bar Harbor, ME, USA) at 6 weeks of age. Upon arrival at our facility, mice were given either reverse osmosis (RO) drinking water or RO water supplemented with $0.5 \mathrm{~g}$ streptomycin sulfate (MP Biomedicals, Solon, OH, USA) per $250 \mathrm{~mL}$ RO water and allowed to drink ad libitum for various durations depending on the experimental design depicted in section "Results." Water bottles containing streptomycin were replaced twice weekly. For $\mathrm{SeV}$ inoculation, mice were sedated with a ketamine xylazine mixture and inoculated intranasally with $30 \mu \mathrm{L}$ of $2 \times 10^{5}$ plaque forming units $\mathrm{SeV}$ (Fushimi strain;
American Type Culture Collection, Manassas, VA, USA) or UV inactivated $\mathrm{SeV}$ (UV-SeV), as we have previously described (31). All experiments were approved by the Institutional Animal Care and Use Committee.

\section{Real-Time Polymerase Chain Reaction (PCR), Flow Cytometry, and Cytokine Microarray}

Real-time PCR assays were performed as we have previously reported $(31,32)$. Messenger RNA was isolated from whole lungs of mice with TRIzol (Invitrogen, Carlsbad, CA, USA). Complementary DNA was made using Quanti-Tect Reverse Transcription kit (Qiagen, Valencia, CA, USA). Real-time PCR assays were performed on the StepOnePlus PCR system using TaqMan Fast Universal PCR master mix (Applied Biosystems, Carlsbad, CA, USA). SeV primer and probes were a gift from Michael J. Holtzman and Eugene Agapov (Washington University, St. Louis, MO, USA). TaqMan gene expression arrays (Applied Biosystems) were used for Il6 (Mm00446190_m1), Ifny (Mm99999071_m1), and Ccl2 (Mm00441242_m1). Specific gene copy numbers were normalized to Gapdh (4352339E; Applied Biosystems).

Flow cytometry was performed as we have previously reported $(31,32)$. Whole lungs and the distal $15 \mathrm{~cm}$ of the small intestine were removed from selected mice and incubated in digest media for $45 \mathrm{~min}$ followed by the addition of EDTA ( $2 \mathrm{mM}$ final concentration) for $15 \mathrm{~min}$. Digest medium consisted of Dulbecco's modified Eagle's media supplemented with 5\% fetal calf serum, sodium bicarbonate, penicillin/streptokinase, $10 \mathrm{mM}$ Hepes, $250 \mathrm{U} / \mathrm{mL}$ collagenase I (Worthington Biochemical), $50 \mathrm{U} / \mathrm{mL}$ DNase I (Worthington Biochemical), and $0.01 \%$ hyaluronidase (Sigma-Aldrich, St. Louis, MO, USA) with or without $0.5 \mathrm{mg}$ Brefeldin A (Sigma-Aldrich) in DMSO. The samples were filtered and the single cell suspension was treated with Red Blood Cell Lysing Buffer (Sigma-Aldrich) with or without Brefeldin A. APC-, FITC-, or PE-labeled antibodies against murine Mac-3/ CD107b (clone M3/84), NK1.1 (clone PK 136), CD4 (clone RM45), CD8 (clone 53-6.7), CD3e (clone 145-2C11), CD11b (clone M1/70), CD11c (clone N418), FceRI (clone MAR-1), anti-mouse Lineage Cocktail (catalog \#133305), and isotype controls IgGs (rat and Armenian hamster) were obtained from BioLegend (San Diego, CA, USA), eBioscience (San Diego, CA, USA), and/or BD Pharmingen (San Jose, CA, USA). For evaluation of depletion efficiency, anti-NK1.1 (clone 694370) and IgG2a control were obtained from R\&D Systems (Minneapolis, MN, USA), and anti-CD4 (clone GK1.5) and IgG2b control (clone LTF-2) were obtained from BioXCell (West Lebanon, NH, USA). APC-labeled tetramer for the immunodominant epitope of $\mathrm{SeV}$ nucleoprotein $\left(\mathrm{NP}_{324-332}\right)$ (35) was obtained from the NIH Tetramer Core Facility (Atlanta, GA, USA). Cells were treated with FC Block (ATCC, Manassas, VA, USA) stained with the above antibodies and analyzed on a FACSCalibur (BD Biosciences, San Jose, CA, USA).

For intracellular staining experiments, cells were isolated from mouse lungs in digest media supplemented with $20 \mathrm{mg} / \mathrm{mL}$ brefeldin A (Sigma-Aldrich). The single cell suspension was stained for surface markers as above in PBS/0.5\% BSA supplemented 
with $20 \mathrm{mg} / \mathrm{mL}$ brefeldin A. Following this, the cells were washed and then incubated overnight at $4^{\circ} \mathrm{C}$ in $1 \%$ paraformaldehyde. The next morning cells were permeabilized with $50 \mu \mathrm{L}$ Triton-X (MidSci, St. Louis, MO, USA) in $50 \mathrm{~mL} \mathrm{PBS/0.5 \%} \mathrm{BSA.} \mathrm{Cells}$ were then stained with APC-labeled anti-mouse IFN $\gamma$ antibody (clone XMG1.2), Foxp3 antibody (clone FJK-16s), or control APC-labeled anti-mouse IgG1א (clone RTK 2071-for IFN $\gamma$ ) or IgG2aк (clone eBM2a-for Foxp3) from eBioscience and/ or BioLegend. Samples were analyzed on a FACSCalibur. Flow cytometry data were analyzed with Flow Jo software (Tree Star Inc., Ashland, OR, USA).

Bronchoalveolar lavage (BAL) cytokines were measured using an ELISA based array (Quansys Biosciences, Logan, UT, USA). After euthanizing mice, the pulmonary circulation was cleared of blood by injection of $1 \mathrm{~mL}$ sterile PBS into the right cardiac ventricle. The trachea was then cannulated with a $22-\mathrm{G}$ catheter and BAL performed with $1 \mathrm{~mL}$ of sterile PBS. IL- $1 \alpha$, IL-1 $\beta$, IL-2, IL-3, IL-4, IL-5, IL-6, IL-10, IL-12p70, IL-17, TNF, IFN $\gamma$, GMCSF, CCL2, CCL3, CCL5, CCL11, CCL17, CCL22, and CXCL1 were measured using an ELISA based array (Quansys Biosciences, Logan, UT, USA). The array was developed on the Li-Cor Odyssey according to the manufacturer's instructions and analyzed with Q-View software (Quansys Biosciences, UT, USA).

\section{Adoptive Transfer of Regulatory T Cells (Tregs)}

Splenocytes were isolated from naive Foxp $3^{g f p}$ mice and sorted into $\mathrm{CD}^{+} / \mathrm{Foxp}^{+}$(Treg) and $\mathrm{CD}^{+} / \mathrm{Foxp}^{-}$(effector T cells; Teff) based on scatter and CD4/GFP expression by flow cytometry. $10^{6}$ Treg or effector $\mathrm{T}$ cells were then injected i.p. into recipient C57BL6 mice that had been on $\mathrm{RO}$ water or RO water supplemented for 2 weeks with streptomycin. The mice were then inoculated with $\mathrm{SeV}$ and survival monitored.

\section{IFN $\gamma$ Blockade and Cellular Depletion}

On days 5 and 9 PI SeV, 0.1, 1, 10, or $100 \mu \mathrm{g}$ of anti-mouse IFN $\gamma$ antibody (clone XMG1.2) or control rat IgG1 antibody (BioLegend) were injected SQ. For NK1.1 depletion, anti-mouse NK1.1 antibody (clone PK136; BioXCell) or control mouse IgG2a (clone C1.18.4; BioXCell) was used, and for CD4 depletion antimouse CD4 (clone RM4-5; eBioscience) or control rat IgG2b (eBR2a; eBioscience) were used.

\section{Bacterial Genomic DNA Extraction, Quantitative PCR Amplification of 16S rRNA Gene Sequences, and 16S rDNA Sequencing}

Lungs (lung parenchyma), trachea, and distal small intestine (distal $15 \mathrm{~cm}, \mathrm{DSI}$ ), cecum, and large intestine (LI) isolated from experimental animals were weighed and homogenized as described (19). Genomic DNA was extracted from tissues using the Qiagen stool kit as described (19). The abundance of specific bacterial groups was determined by qPCR using the MyiQ singlecolor real-time PCR detection system (Bio-Rad, Hercules, CA, USA) as described (19). Briefly, real-time PCR was done using the IQ SYBR Green Supermix (Bio-Rad), started with an initial step at $95^{\circ} \mathrm{C}$ for $3 \mathrm{~min}$, followed by 40 cycles of $10 \mathrm{~s}$ at $95^{\circ} \mathrm{C}$ and $45 \mathrm{~s}$ at $63^{\circ} \mathrm{C}$. Data were acquired in the final step at $63^{\circ} \mathrm{C}$. Using the same genomic DNA from each sample, real-time PCR reactions were completed using group specific primers to determine the amount of bacteria in each of the following major groups: Eubacterium rectale/Clostridium coccoides (Erec), Lactobacillus sp. (Lact), Bacteroides sp. (Bac), Mouse Intestinal Bacteroides, Segmented Filamentous Bacteria (SFB), and total bacteria. Bacterial numbers were determined using standard curves constructed with reference bacterial plasmid standards containing the $16 \mathrm{~S}$ sequence specific for each bacterial group analyzed. Data are presented as total burden per lung parenchyma or trachea, and bacterial burden per gram of intestinal tissue for the DSI, cecum, and LI.

Sequencing was performed by Diversigen ${ }^{\mathrm{TM}}$ (Baylor College of Medicine). The $16 \mathrm{~S}$ rDNA V4 region amplicons (single index) were produced by PCR and sequenced on the MiSeq platform (Illumina) using the $2 \times 250$ bp protocol yielding pair-end reads that overlap by $247 \mathrm{bp}$ (36). Following sequencing, raw BCL files were retrieved from the MiSeq platform and called into fastqs by Casava v1.8.3 (Illumina). The read pairs were demultiplexed based on unique molecular barcodes, filtered for PhiX using Bowtie2 v2.2.1 (37), and reconstituted into two fastq files for each read using standard BASH. Sequencing Reads were merged (allowing 4 mismatches per $\geq 50$ bases) and processed using USEARCH v7.0.1001 (38). Sequences were demultiplexed using QIIME v1.8.0 (39) and then clustered using the UPARSE pipeline (38). Operational taxonomic unit (OTU) classification was achieved by mapping the UPARSE OTU table to the SILVA database (40). Abundances were recovered by mapping the demultiplexed reads to the UPARSE OTUs. A custom script constructed an OTU table from the output files generated in the previous two steps.

\section{Bioinformatic Analysis}

Microbiota data were analyzed using the Vegan 1.17-9 (41) and Ecodist 1.2.2 (42) packages in R 3.0.2 (43). Raw data, counts per genus-level OTU, were used to assess sample Simpson diversity. Microbiota data normalized to average sequencing depth were used to assess inter-sample Bray-Curtis beta diversity, sample clustering, and Non-metric Multidimensional Scaling Ordination (NMDS). Two antibiotic-treated lung samples failed sequencing and were excluded from subsequent data analysis. Statistical significance for differences in microbiota diversity between treatment groups was determined using Adonis (44). Normalized data were then log-transformed: $\log _{10}$ (abundance +1$)$ for heteroscedastic Student's $t$-test to find differences in microbiota abundance between treatment groups. $T$-test $p$-values were not corrected for multiple testing due to the relatively small number of tests performed, 30 for the cecum samples and 40 for the lung samples.

\section{Statistical Analysis}

Survival data presented as Kaplan-Meier survival curves and statistical significance calculated by the Log-rank/Mantel-Cox test. Other data are presented as mean with statistical significance calculated by Student's $t$-test or $\chi^{2}$ test (for dose-response to antiIFN $\gamma$ treatment). In all cases, $p<0.05$ was considered statistically significant. 


\section{RESULTS}

\section{Alteration of Intestinal Microbiota Increases Mortality From a Pulmonary Viral Infection}

To determine if intestinal microbiota could alter an immune response in the lungs, we took advantage of the antibiotic streptomycin and the well-characterized SeV infection model. Streptomycin is a non-absorbable antibiotic that has been shown only to affect bacterial load in the gastrointestinal tract with only $0.00001 \%$ being absorbed when given at high doses (45). Therefore, streptomycin treatment should have minimal to no effect on bacterial species in the lung. We placed C57BL6 mice on RO water or RO water supplemented with streptomycin. After 2 weeks, the mice were then infected with either $\mathrm{SeV}$ or UV-SeV. Normally, SeV infection leads to $<5 \%$ mortality in infected mice (33). However, as shown in Figure 1A, mice that had been placed on streptomycin containing water had a marked and significant increase in mortality from $\mathrm{SeV}$ infection by days 10-12 PI with virus. This increase in mortality required an active viral infection, as mice inoculated with UV-SeV all survived regardless of antibiotic exposure.

Although streptomycin is not absorbed into the systemic circulation, it was still possible that the increased mortality resulted from a direct effect of the antibiotic on the antiviral immune response. However, as shown in Figure 1B, increased mortality was not seen when mice were given streptomycin for 1 week before (groups A and B) or just throughout the viral infection period (group C). In fact, the increase in mortality was seen only when 2 weeks of antibiotic therapy was given before viral infection (group D). This suggested that the effect of altering the intestinal microbiota required time to translate to the pulmonary mucosal immune response.

\section{Streptomycin Treatment Significantly Reduces Intestinal but Not Lung Microbiota Diversity}

The protective and functional capacity of the microbiota depends on its composition, including species abundance and diversity. To determine the effect of streptomycin treatment on the richness of bacterial diversity, we used $16 \mathrm{~S}$ high-throughput sequencing to examine the bacterial colonization of the cecum and lung.

The microbiota composition of the cecum was predominantly Clostridiales (Lachnospiraceae and Ruminococcaceae), Bacteroides, and Erysipelotrichales (Erysipelotrichaceae). Antibiotic treatment significantly altered the microbiota in the cecum (Figure 2A). Detectable OTU count was reduced by $50 \%\left(p=4.5 \times 10^{-5}\right)$, and the Simpson alpha diversity metric (Figure 2B) was reduced by $85 \%\left(p=1.5 \times 10^{-9}\right)$. Most of the bacterial taxa were reduced to undetectable levels with the exception of Bacillales (Paenibacillaceae and Planococcaceae), which were relatively increased by 14,000 and 30 -fold, respectively. Changes in microbiota abundance were validated by qPCR (Figure 3 ), with similarly characterized changes in the small and large intestines.

The microbiota composition in the lung was predominantly Bacillales (Paenibacillaceae) and Clostridiales (Lachnospiraceae and Ruminococcaceae). As expected with a non-absorbable
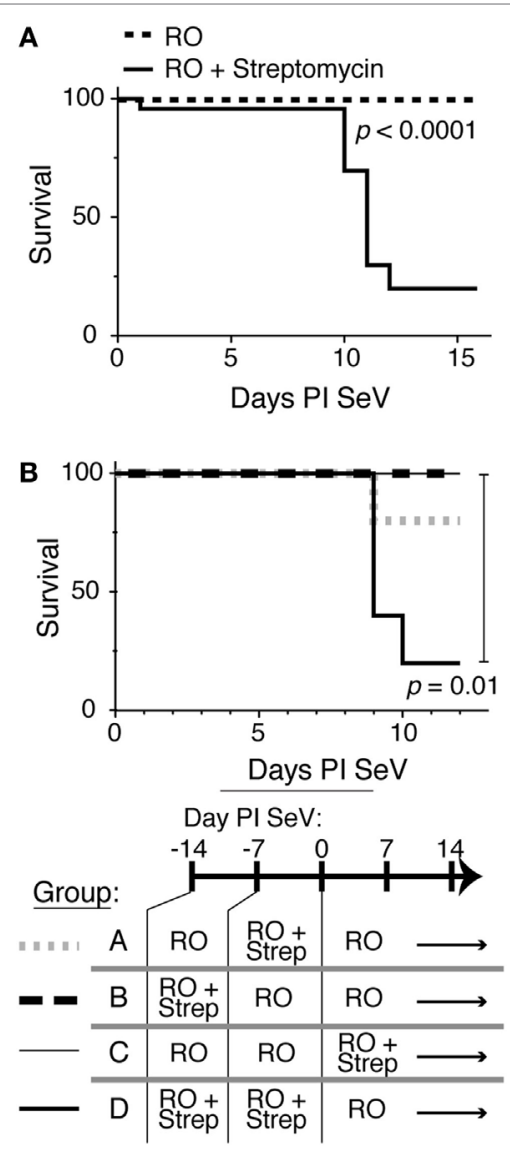

FIGURE 1 | Disruption of intestinal microbiota results in increased mortality to respiratory Sendai virus (SeV) infection. (A) Kaplan-Meier survival curve for C57BL6 mice maintained on reverse osmosis $(\mathrm{RO})$ water or $\mathrm{RO}$ water supplemented with $0.5 \mathrm{~g} / 250 \mathrm{~mL}$ of the non-absorbable antibiotic streptomycin ( $\mathrm{RO}+$ streptomycin) for 2 weeks prior to inoculation with $2 \times 10^{5}$ plaque forming units $\mathrm{SeV}(\mathrm{RO}, n=26$; $\mathrm{RO}+$ streptomycin, $n=23$; data combined from six separate experiments, $n \geq 3$ mice/treatment each). (B) Two weeks of $\mathrm{RO}+$ streptomycin water before the viral infection is sufficient to drive the increased mortality. Kaplan-Meier survival curve for mice exposed to $\mathrm{RO}$ or $\mathrm{RO}+$ streptomycin $(\mathrm{RO}+$ strep) water for the indicated time periods ( $n=5 /$ group).

antibiotic, streptomycin treatment did not induce significant changes in the lung microbiota. However, two treated lung samples failed sequencing and were excluded from subsequent data analysis. OTU count and Simpson diversity were comparable before and after treatment (Figures 2D,E). Analysis of the microbiota abundance suggested small changes in Clostridiales (Lachnospiraceae) and Lactobacillales (Lactobacillaceae and Enterococcaceae). However, analysis of the sequencing data revealed weak $p$-values $(0.02,0.02$, and 0.04$)$, which could not be validated by qPCR (Figure 3), suggesting that these changes were not significant. We, however, cannot completely rule out changes in specific low abundance species nor can we completely rule out a role for antibiotics in the failure of two of the treated lung samples.

Beta diversity analysis using the Bray-Curtis metric highlighted the dramatic change in composition induced by antibiotic treatment in the cecum. NMDS ordination showed control and 


\section{Cecum}

A

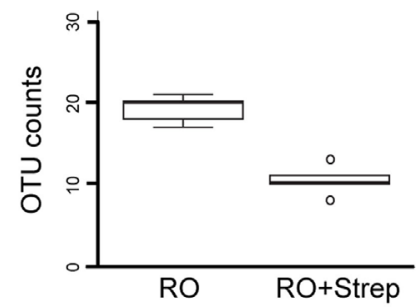

B

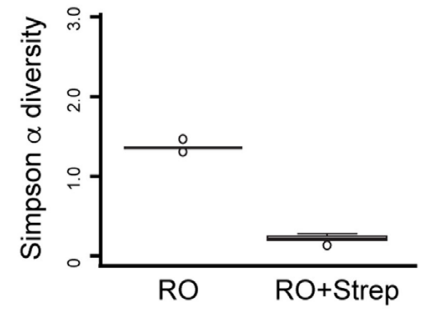

\section{Lung}

D

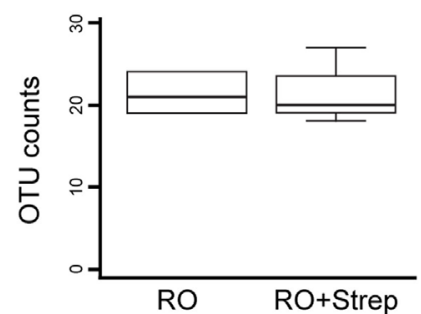

E

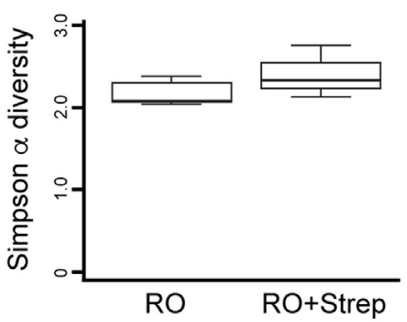

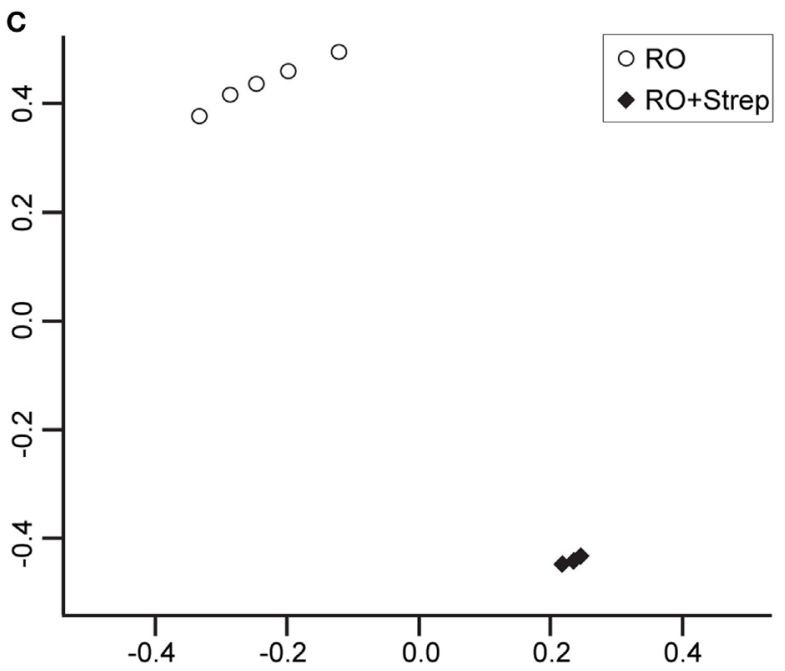

F

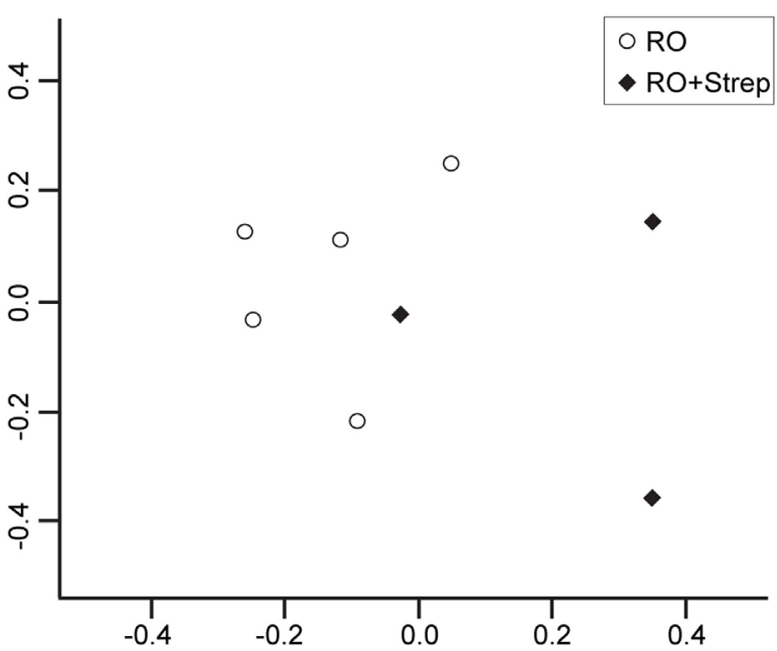

FIGURE 2 | Streptomycin treatment reduces the abundance and diversity of cecal but not lung microbiota. DNA was isolated from cecum (A-C) and lung (D-F) after 2 weeks of reverse osmosis $(\mathrm{RO})$ or $\mathrm{RO}+$ streptomycin treatment, and analyzed for microbial composition. Operational taxonomic unit (OTU) counts (A,D) and alpha diversity (B,E) were compared between treatment groups. Beta diversity was compared using Non-metric Multidimensional Scaling Ordination of the Bray-Curtis beta diversity metric (C,F). (A) Significant differences were seen in cecal OTU count $\left(p=4.5 \times 10^{-5}, n=5\right),(\mathbf{B})$ Simpson alpha diversity index $\left(p=1.5 \times 10^{-9}, n=5\right)$, and (C) beta diversity (Adonis $p=0.012, n=5$, note that two treated samples were so close to the others that the treated group appears as only three samples). No significant differences were noted in lung microbiota (D) OTU composition, (E) Simpson alpha diversity index, or (F) beta diversity between antibiotic-treated $(n=3)$ and -untreated $(n=5)$ mice.

treated cecum samples cluster distinctly (Adonis $p$-value $=0.012$, Figure 2C), while the lung samples were intermixed (Figure 2F).

\section{Altering Intestinal Microbiota Leads to Dysregulated Pulmonary Immune Response to SeV}

One possible cause for increased mortality in mice exposed to streptomycin before viral infection would be a failure to adequately control and clear the virus. To assess this possibility, we examined viral titers by qPCR. In wild-type C57BL6 mice, SeV titers peak around day 3-5 PI and essentially clear by day 12 PI (33). As can be seen in Figure 4A, treatment with streptomycin for 2 weeks before viral inoculation led to a small but significant decrease in viral clearance at day 8 PI. However, by day 10 PI, viral titers were identical regardless of treatment. Since the increased mortality was seen at day 10-12 PI, the half-log difference seen at day $8 \mathrm{PI}$ is not sufficient to explain the increased death. 


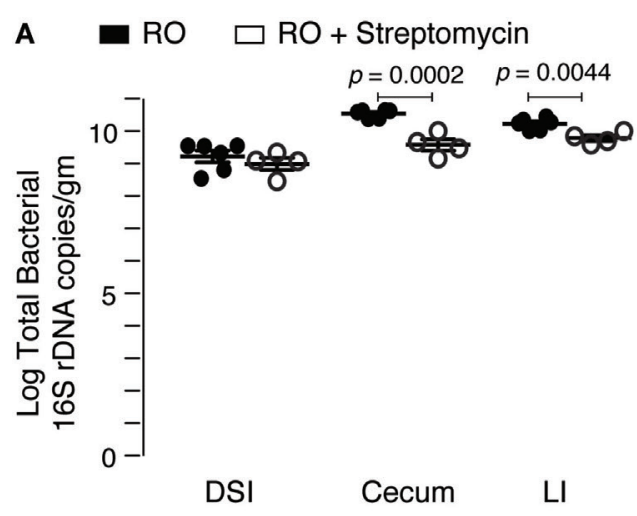

B Distal Small Intestine

- RO $\square \mathrm{RO}+$ Streptomycin
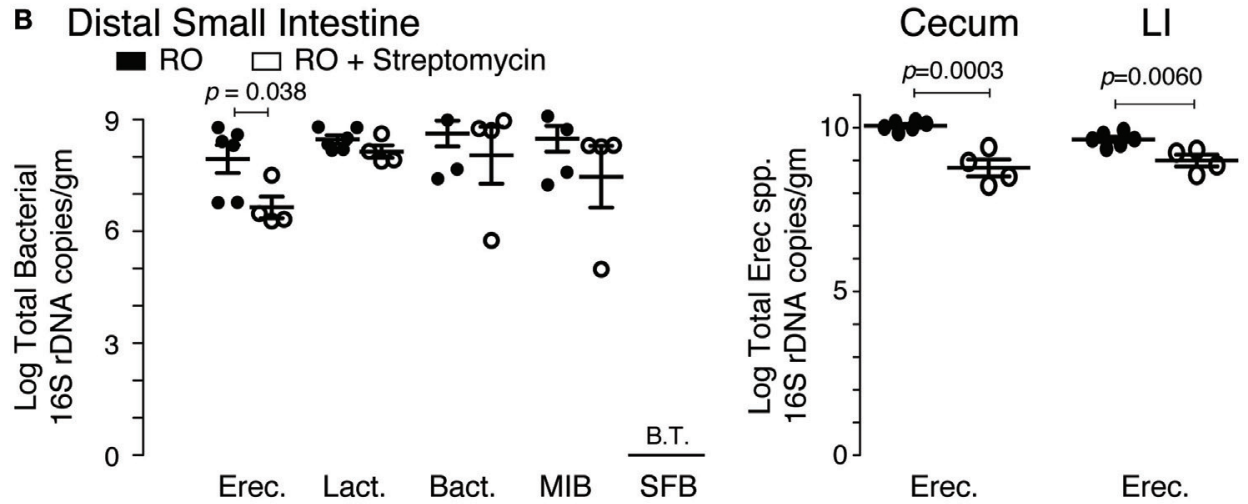

\section{c Trachea}

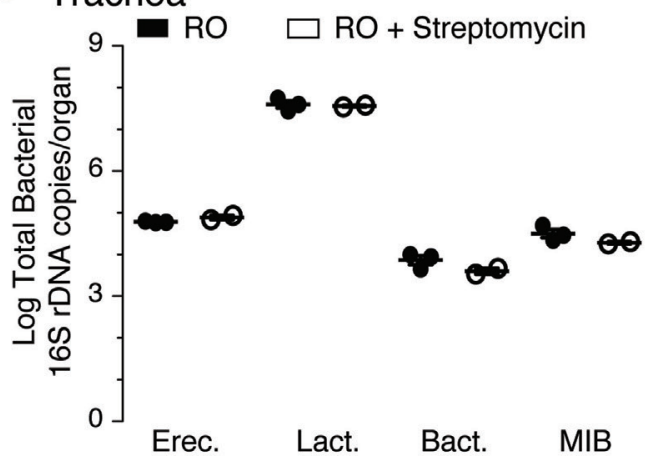

\section{Lung Parenchyma}

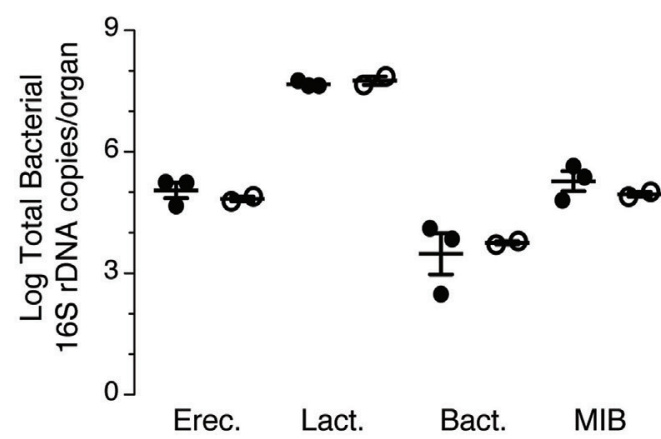

FIGURE 3 | qPCR validation of streptomycin effect on intestinal and lung microbiota. (A) Total bacterial load (16S rDNA copies) in the intestinal and pulmonary compartments from mice exposed to 2 weeks of either reverse osmosis (RO) or RO + streptomycin water. Abbreviations: DSI, distal small intestine; LI, large intestine ( $n=4-6$ mice/group/tissue location). (B) Specific bacterial groups identified in the distal small intestine (left panel) and Erec spp. in the cecum and LI (right panel) from mice treated as in panel (A). (C) Specific bacterial groups identified in the trachea (left) and lung parenchyma (right) from mice treated as in panel (A). Microbiota determined by $16 \mathrm{~S}$ qPCR, with quantities expressed as log total bacterial species per gram of intestinal sample or log total bacterial species per lungs or trachea ( $n=2-6$ mice/group/tissue location). Abbreviations: Erec, Eubacterium rectale/Clostridium coccoides, Lact, Lactobacillus, Bact, Bacteroides, MIB (S24-7), Mouse intestinal Bacteroides, SFB, Segmented filamentous bacteria, B.T., below threshold.

We next questioned whether the cytokine response was dysregulated in $\mathrm{SeV}$ infected streptomycin-treated mice. Using BAL fluid obtained from mice 8 days $\mathrm{PI} \mathrm{SeV}$, we performed a protein microarray (Figure 4B). Of the 20 cytokines and chemokines assayed, 6 were statistically increased with streptomycin treatment. Of these, the most highly expressed (i.e., in ng/mL concentrations) were IL-6, IFN $\gamma$, CCL2 (monocyte chemoattractant protein-1, MCP-1), and CCL11 (eotaxin). While CCL11 levels doubled with streptomycin exposure, they were unlikely to play a major role in the immune response, since $\mathrm{SeV}$ infection in C57BL6 mice is not associated with lung or BAL eosinophilia (primary target of CCL11). Of the other cytokines, IFN $\gamma$ production was most increased with streptomycin exposure (4.4 versus 3.6-fold for CCL2 and 1.6-fold for IL-6), suggesting that it might be responsible for the increased mortality.

We next determined if the increase in pro-inflammatory cytokines required a live viral infection. Examining whole lung 

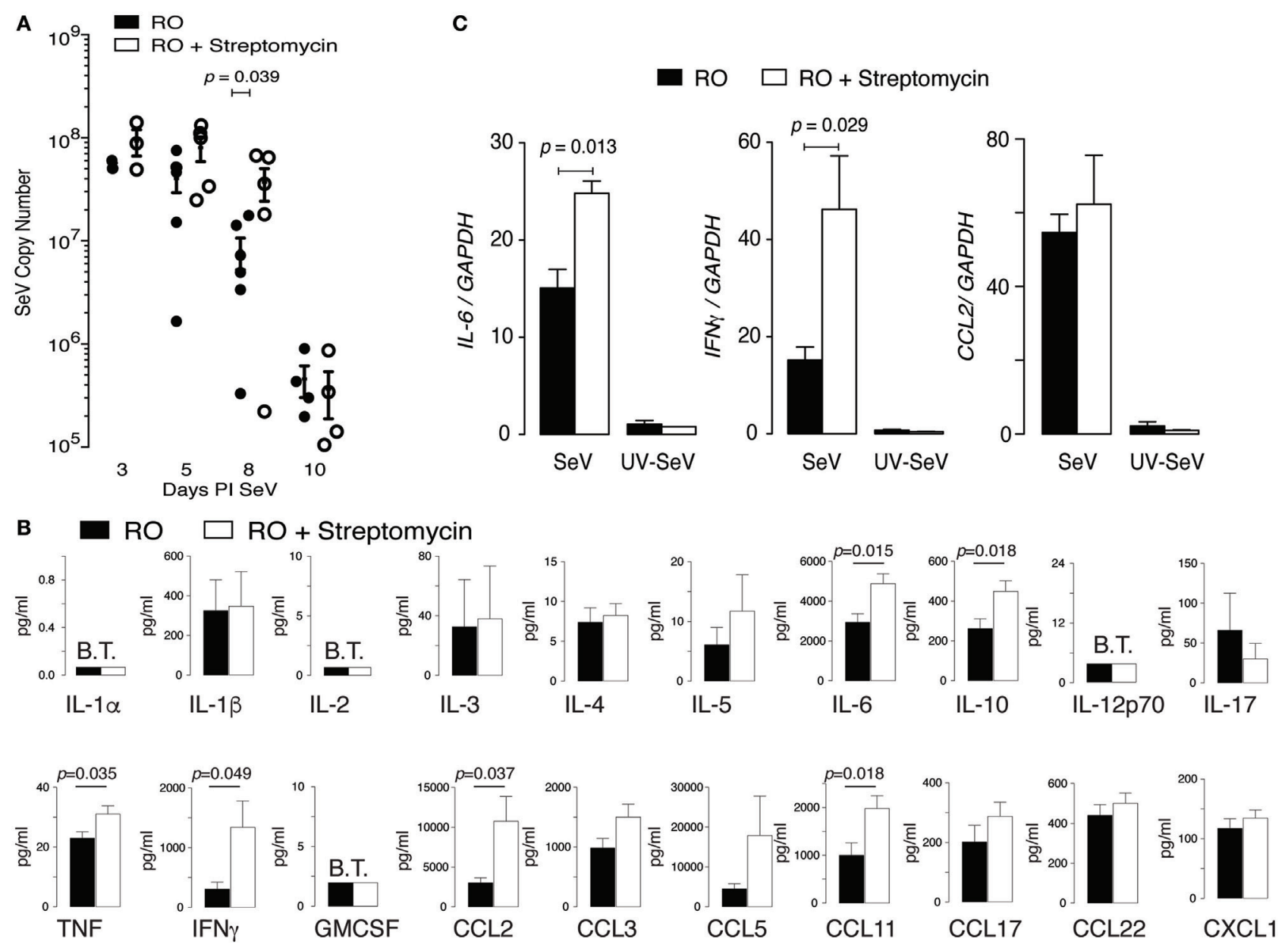

FIGURE 4 | Altered intestinal microbiota augments pulmonary cytokine response to Sendai virus (SeV), but does not impair viral clearance. Mice were placed on reverse osmosis $(\mathrm{RO})$ or $\mathrm{RO}+$ streptomycin water, and 2 weeks later inoculated with $\mathrm{SeV}$. (A) RT polymerase chain reaction (PCR) quantification of SeV copy number in whole lungs at the indicated days post inoculation (PI) SeV ( $n=3-6$ mice/day and group). (B) Expression of cytokines in the bronchoalveolar lavage fluid of mice 8 days PI SeV. Data are array results from a commercially available ELISA protein array (data combined from five separate experiments with $n \geq 2 /$ group/ experiment, with samples run in duplicate); note increased IL-6, IFN lung of SeV-infected mice that had received streptomycin. Specific cytokine mRNA levels were assessed by RT PCR in whole of lung of mice at day 8 PI SeV or UV inactivated SeV ( $n=3$ /group and treatment) and normalized to Gapdh copy number.

at day 8 PI SeV or UV-SeV we found streptomycin treatment led to a statistically significant augmentation in Il6 and If $n \gamma$ mRNA in infected mice, while uninfected mice had no such increase in these pro-inflammatory gene products (Figure 4C). Ccl2 mRNA was unaffected by streptomycin treatment, although it was clearly induced in a viral-specific fashion. Since streptomycin treatment increased CCL2 protein without a concomitant increase in mRNA levels, CCL2 production likely is controlled in a post-translational fashion. The augmentation in both IL- 6 and IFN $\gamma$ production, on the other hand, appeared to be transcriptionally regulated as both protein and mRNA were induced with streptomycin treatment.

\section{Increased Mortality Is due to Overproduction of IFN $\gamma$}

Overproduction of IFN $\gamma$ during an immune response is well known to be fatal (46). Therefore, we hypothesized that increased production of IFN $\gamma$ could be contributing to the excess mortality in mice that had ingested streptomycin prior to viral inoculation. To test this hypothesis, we placed mice on $\mathrm{RO}+$ streptomycin for 2 weeks before infecting them with $\mathrm{SeV}$. On day 5 and $9 \mathrm{PI} \mathrm{SeV}$, mice were given either an anti-IFN $\gamma \mathrm{mAb}$ or IgG control $\mathrm{mAb}$ SQ and mortality monitored. As demonstrated in Figure 5A, injection with an anti-IFN $\gamma$ mAb completely prevented mortality to $\mathrm{SeV}$ infection. In fact, using decreasing doses of anti-IFN $\gamma \mathrm{mAb}$, we were able to show a statistically significant dose-response in $\mathrm{SeV}$-induced mortality (Figure 5B). Thus, the increased mortality from $\mathrm{SeV}$ in mice treated with streptomycin appears to be IFN $\gamma$ dependent.

T cells, NK cells, NKT cells, innate lymphoid cells (ILCs) including lymphoid tissue inducer (LTi), a subclass of ILCs, and macrophages are all cell types known to produce IFN $\gamma$. Therefore, to determine if streptomycin exposure altered the adaptive immune response to $\mathrm{SeV}$, we examined whether lung $\mathrm{T}$ cell numbers were changed in mice treated with the antibiotic. Although SeV-specific 


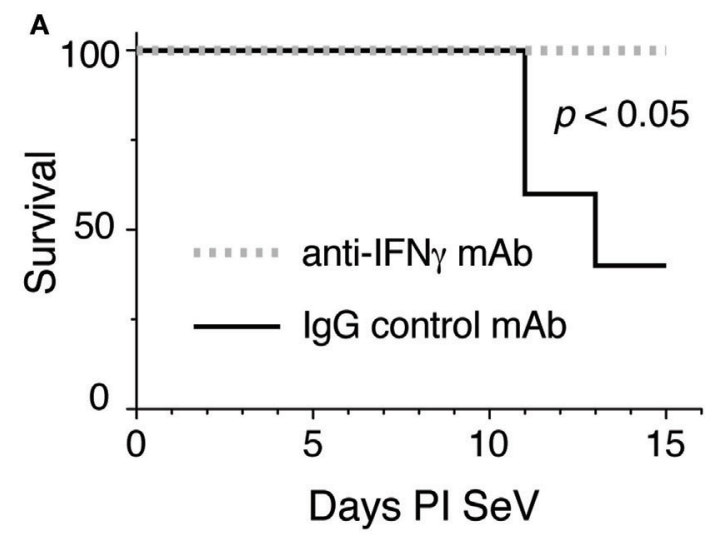

C $\square$ RO $\square$ RO + Streptomycin

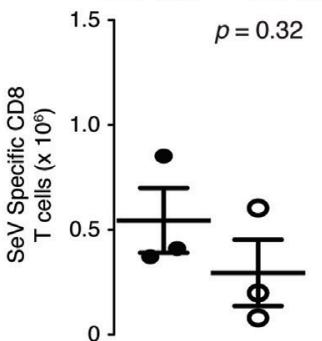

SeV specific CD8 T cells

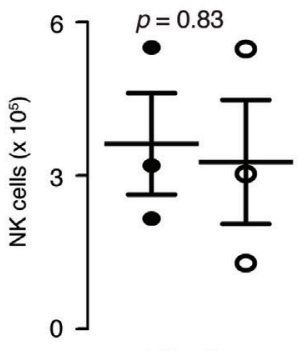

NK cells
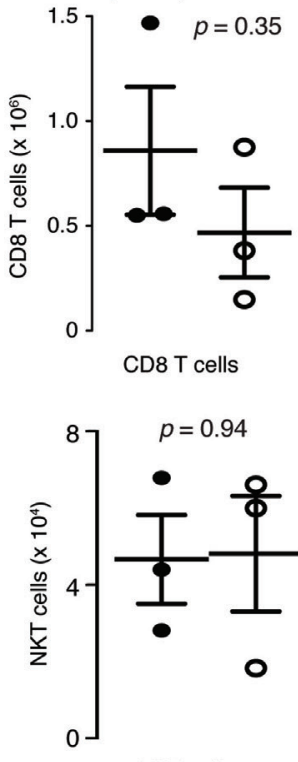

NKT cells

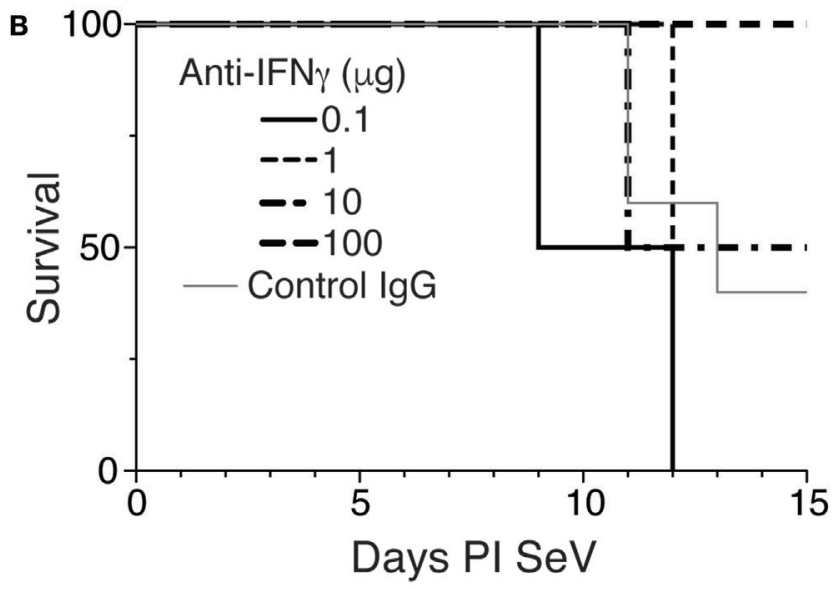

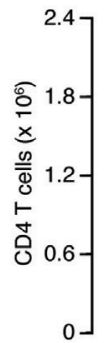

$p=0.52$

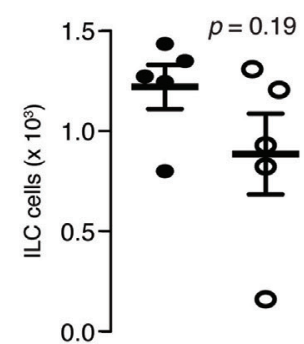

CD4 T cells

Lin- CD4+ (ILC)

D

$\mathrm{RO}+$ Streptomycin
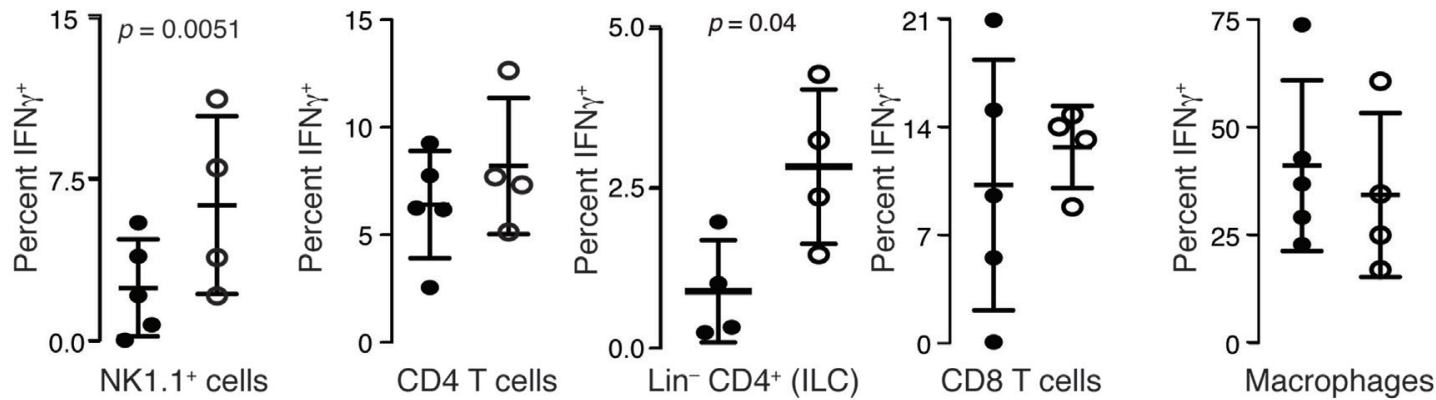

FIGURE 5 | Increased mortality in streptomycin-treated mice is IFNy dependent. (A) Mice were given streptomycin for 2 weeks before infection with Sendai virus (SeV). At day 5 and $9 \mathrm{PI} \mathrm{SeV}, 100 \mu \mathrm{g}$ of an IFN $\gamma$ blocking or control IgG monoclonal antibody was given SQ and mortality measured ( $n=5 / \mathrm{group})$. (B) Mice were treated as in panel (A) but with the indicated doses of anti-IFN $\gamma$ antibodies being administered $\left(n=5 /\right.$ group). $p<0.04$ for dose-response $\left(\chi^{2}\right)$. (C) No difference was noted in the number of SeV-specific CD8 ${ }^{+} T$ cells, total CD8 ${ }^{+} T$ cells, total CD4+ $T$ cells, NK cells (CD3-NK1.1 lymphocytes), NKT cells (CD3+NK1.1+ lymphocytes), innate lymphoid cells ( $\mathrm{Lin}^{-} \mathrm{CD} 4^{+}$lymphocytes), and macrophages (Mac3+) at 8 days PI SeV in the lungs of mice treated with reverse osmosis (RO) or

$\mathrm{RO}+$ streptomycin ( $n=3-5$ mice/group). (D) IFNy from NK1.1, CD4, CD8-expressing lymphocytes, CD4+Lin- cells, or lung Mac3+ macrophages was determined by intracellular flow cytometry on day $8 \mathrm{PI} \mathrm{SeV}$. Mean \pm SEM percent of given cell type expressing IFN $\gamma$ is shown ( $n=4-10$ mice/treatment/group). See Figure S1 in Supplementary Material for gating strategy. 
$\left(\mathrm{SeV}\right.$ tetramer $\left.{ }^{+}\right) \mathrm{CD}^{+}$and total $\mathrm{CD}^{+}$and $\mathrm{CD} 4^{+} \mathrm{T}$ cells appeared to be reduced with streptomycin ingestion, none of these changes were significant (Figure 5C). Similarly, no difference was seen in the NK, NKT, or ILC cell compartments, although total lung macrophage numbers were modestly decreased. Together, these data demonstrate that increased IFN $\gamma$ did not come from an increase in the number of IFN $\gamma$-producing cells.

Given no differences in cell numbers, we hypothesized that per-cell IFN $\gamma$ production might be altered in streptomycintreated and $\mathrm{SeV}$-infected mice. Mice were placed on either RO or $\mathrm{RO}+$ streptomycin water for 2 weeks before being infected with $\mathrm{SeV}$. At day $8 \mathrm{PI}$, lung cells were isolated and expression of IFN $\gamma$ determined using intracellular flow cytometry. There was a significant and marked increase in the percent of NK1.1expressing lymphocytes and $\mathrm{Lin}^{-} \mathrm{CD} 4^{+}$cells that were producing IFN $\gamma$ when mice were treated with streptomycin before $\mathrm{SeV}$ infection, whereas the frequency of $\mathrm{CD} 4^{+}$or $\mathrm{CD} 8^{+}$lymphocytes, or lung macrophages producing IFN $\gamma$ was not changed with streptomycin exposure (Figure 5D). Thus, NK1.1+ lymphocytes and/or Lin ${ }^{-} \mathrm{CD}_{4}^{+}$cells could be a source of the increased production of IFN $\gamma$ found in streptomycin-treated, SeV-infected mice.

\section{Disruption of the Intestinal Microbiota Induced Mortality to SeV Is CD4 Not NK1.1 Dependent}

To determine if $\mathrm{NK} 1.1^{+}$cells were necessary for the increased mortality, we gave mice $\mathrm{RO}$ or $\mathrm{RO}+$ streptomycin for 2 weeks before inoculating with SeV. At days 5 and 9 PI SeV, anti-NK1.1 or a control mAb was administered (see Figure S2A in Supplementary Material for depletion efficiency) and mortality measured. As shown in Figure 6A, depletion of NK1.1-expressing cells had no effect on the mortality to SeV.

To determine if CD4-expressing cells were necessary for the increased mortality, we examined the effect of depleting CD4 cells in this model (see Figure S2B in Supplementary Material). As shown in Figure 6B, when mice (on $\mathrm{RO}+$ streptomycin water) were given an anti-CD4 monoclonal antibody on days 5 and 9 PI $\mathrm{SeV}$, they had no mortality, while mice given a control rat IgG still exhibited increased mortality. This demonstrates a requirement for a CD4-expressing cell. The major CD4-expressing cell types are $\mathrm{CD} 4^{+} \mathrm{T}$ cells, macrophages, NKT cells, ILCs (ILC1s), and LTi cells (47).

We next assessed the requirements of CD8-expressing T cells in the model. As shown in Figure $6 \mathrm{C}$ mice deficient in CD8 $\left(C d 8^{-/-}\right)$demonstrated significant mortality with $\mathrm{SeV}$ even when only on RO water. However, mortality was further significantly increased with dysregulation of intestinal microbiota, although there was modest (but significant delay) in mortality when compared with wild-type $(\mathrm{C} 57 \mathrm{BL} / 6)$ mice. Together, this suggests minimal requirement for $\mathrm{CD}^{+} \mathrm{T}$ cells in the increased mortality phenotype.

Thus, increased mortality appeared to be dependent on IFN $\gamma$, and CD4 but not NK1.1 or CD8-expressing cells. Since only NK1.1 $1^{+}$cells and potential ILCs ( $\mathrm{Lin}^{-} \mathrm{CD} 4^{+}$cells) were shown to have increased IFN $\gamma$ production, we presume that ILCs are the likely source of the
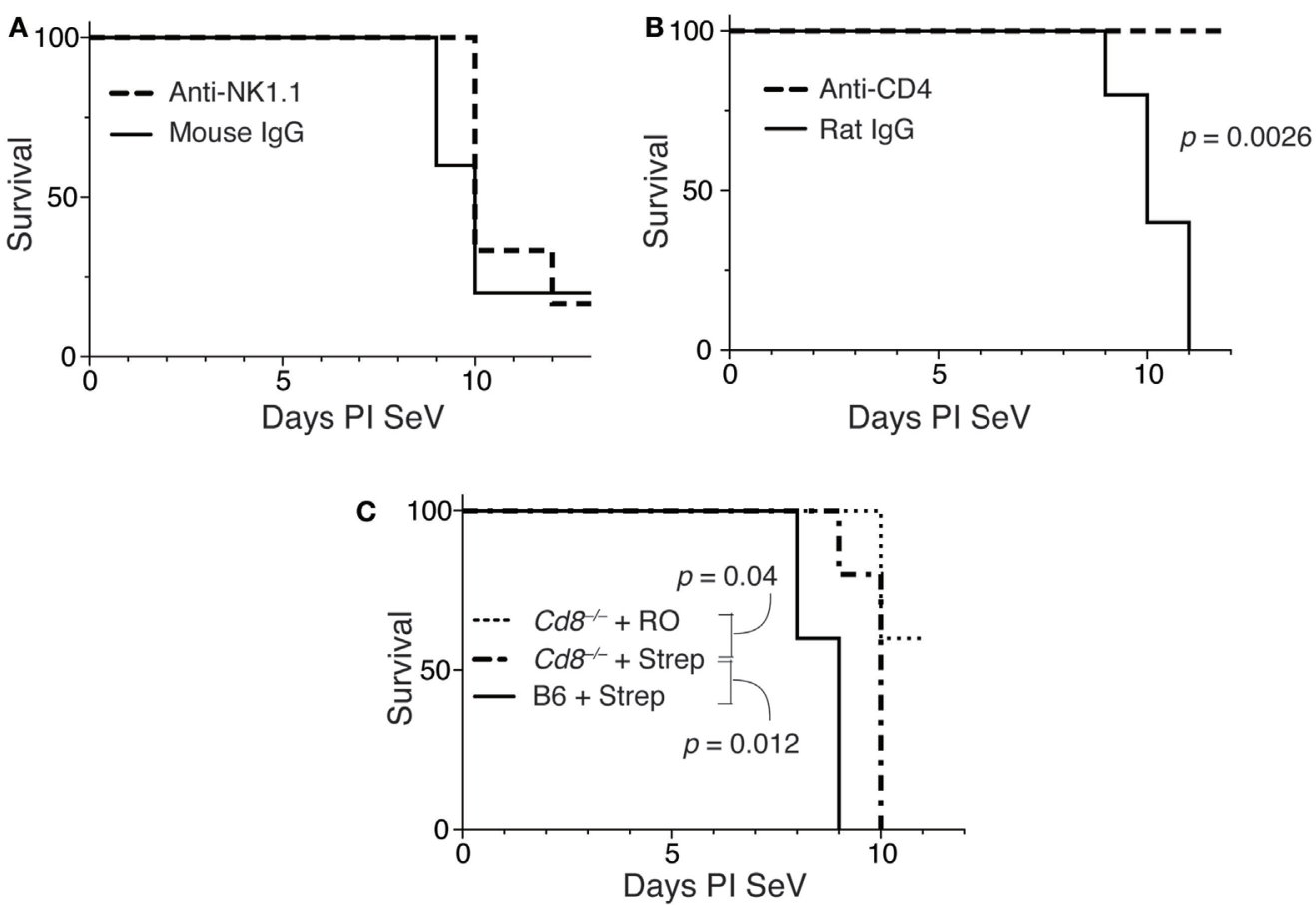

FIGURE 6 | Increased mortality in streptomycin-treated mice requires CD4+ cells, but not IFN $\gamma$-producing CD4 T cells. (A) Mice were treated as in Figure 4, and at day 5 and 9 PI Sendai virus (SeV), $100 \mu \mathrm{g}$ of anti-NK1.1 or control mouse lgG monoclonal antibody was administered SQ. Mortality was then measured. (B) Mice were treated as in panel (A) using anti-CD4 or control rat lgG monoclonal antibodies, and mortality was measured. (C) Wild-type (C57BL/6) or CD8-deficient $\left(\mathrm{Cd}^{-/-}\right)$mice were treated as in panel $\mathbf{( A )}$, and mortality measured. For all of these experiments $n=5 /$ group/treatment. 
IFN $\gamma$. We are unable to verify ILCs as the source of IFN $\gamma$ because the currently available ILC-deficient mice (i.e., Ragy ${ }^{-/-}$) also lack T and B cells, and, thus, would rapidly succumb to SeV infection (48). However, as mentioned, the lack of an increase in IFN $\gamma$ from $\mathrm{CD}^{+}$ $\mathrm{T}$ cells and macrophages, as well as the fact that the anti-NK1.1 treatment did not prevent mortality, suggests that the increased IFN $\gamma$ came from the lineage negative population.

\section{Streptomycin Reduces Tregs, Which Are Required to Prevent Mortality}

We next hypothesized that alteration in intestinal microbiota might lead to disruption of a regulatory component in the lung. One controller of the adaptive immune response is the Treg, so we examined the effect of streptomycin treatment on Treg numbers in the lung and gut. Surprisingly, Tregs were significantly reduced in the lung parenchyma with streptomycin treatment (Figure 7A). In addition, antibiotic treatment led to an almost complete absence of Foxp $3^{+}$Tregs in the distal small intestine. This effect was sustained in the lung during infection with $\mathrm{SeV}$ (Figure 7B). In the gut, $\mathrm{SeV}$ infection reduced Treg numbers in both $\mathrm{RO}$ and $\mathrm{RO}+$ streptomycin-treated animals (compare Figures 7A,B); however, the difference between the two treatments was not significant with $\mathrm{SeV}$ infection $(p=0.11)$. At present, we are unable to explain the reason why $\mathrm{SeV}$ infection shows a lower trend for Tregs numbers even without antibiotic treatment. To determine if loss of Tregs was responsible for the increased mortality, we performed adoptive transfer experiments. Mice were kept on streptomycin or RO water for 2 weeks then given $1 \times 10^{6}$ splenic Tregs via i.p. injection and then inoculated i.n. with $\mathrm{SeV}$ the same day and mortality monitored over time. We have used Tregs derived from splenocytes because they are routinely used in adoptive transfer

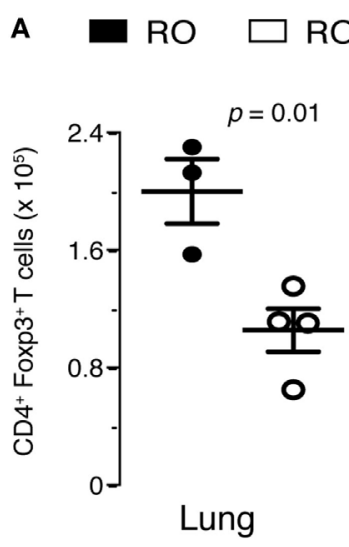

Lung
RO + Streptomycin

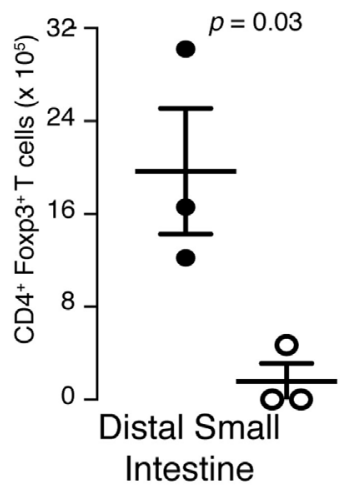

B RO

$\mathrm{RO}+$ Streptomycin

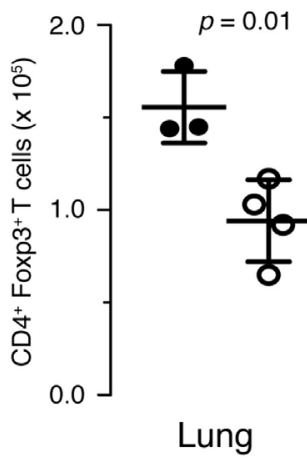

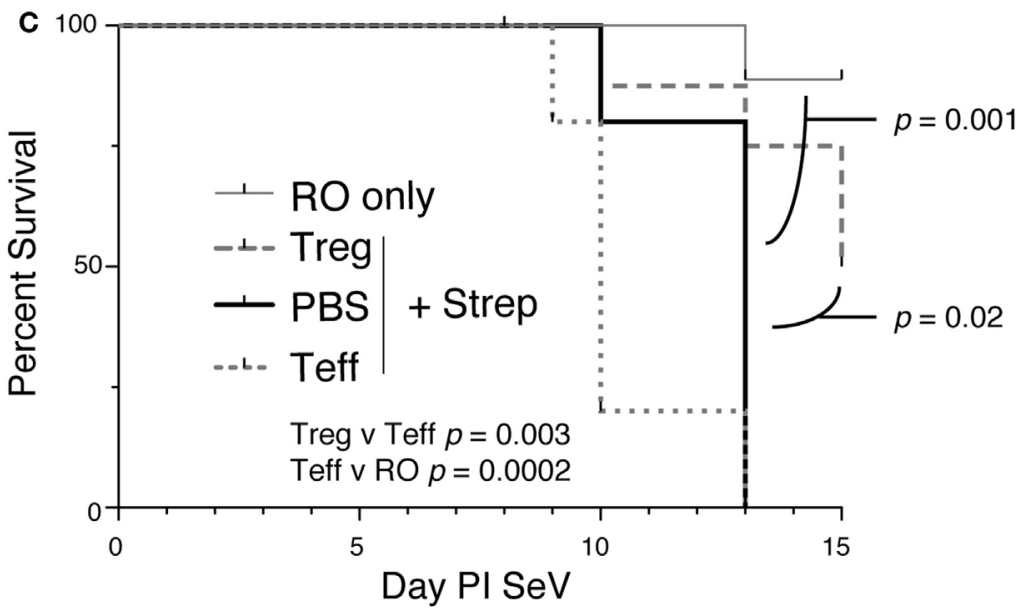

FIGURE 7 | Disruption of intestinal microbiota reduces lung and intestinal regulatory T cells (Tregs), which are needed to prevent increased mortality to Sendai virus (SeV). (A) Foxp3+ Tregs isolated from the lung or distal small intestine from mice treated with 2 weeks of reverse osmosis $(\mathrm{RO})$ or $\mathrm{RO}+$ streptomycin $(n=3-5$ mice/ group). (B) Mice treated as in panel (A) but after 2 weeks of $\mathrm{RO}$ or $\mathrm{RO}+$ streptomycin water the mice were infected with SeV and number of Foxp3 ${ }^{+}$Tregs determined at day $8 \mathrm{PI} \mathrm{SeV} \mathrm{(} n=3-4$ mice/group). (C) Adoptive transfer of CD4+/Foxp3+ Treg but not CD4+/Foxp3- effector T (Teff) cells at the time of SeV infection prevents the increased mortality seen in mice given 2 weeks of streptomycin before viral infection. RO only = mice given RO water and infected with SeV without any transfer of cells; Treg + Strep, PBS + Strep, and Teff + Strep are mice given 2 weeks of streptomycin followed by adoptive transfer of the given cells and SeV inoculation ( $n \geq 5$ mice/group, data combined from two separate experiments). 
studies and have shown to resolve lung inflammation, injury, and lethality due to Treg deficiency (49-51). Transferring Treg but not effector $\mathrm{CD}^{+} \mathrm{T}$ cells (Teff) significantly reduced the viral induced mortality in SeV-infected mice (Figure 7C). Interestingly, while not statistically significant, there was a trend $(p=0.064)$ for increased mortality with transfer of Teff cells, supporting our CD4 depletion data (Figure 6B). It is worth noting that ILCs would have been included in our Teff cell population (since they express CD4) and could have led to the trend for increased mortality with Teff transfer. Taken together, these data suggest that modulating the intestinal microbiota before a respiratory viral infection will drive a dysregulated immune response characterized by both a reduction in lung Tregs and an increase in IFN $\gamma$ production that together lead to increased mortality.

\section{DISCUSSION}

We are only beginning to understand the importance of commensal microbiota in modulating host immune responses. Most prior studies have focused on the intestinal microbiota and intestinal immune response; for example, the presence of SFB was associated with the development of Th17 cells $(2-4,52)$, and intestinal microbiota appear critical for intestinal Treg development (7-9). There is evidence that intestinal microbiota influences systemic disease development, including obesity (12), non-alcoholic fatty liver disease (53), experimental allergic encephalomyelitis (5), and autoimmune arthritis (6). However, few studies have been related to the lung, and most focused on disease correlation not immune mechanism (17). Nonetheless, several studies have shown a potential effect of reduced microbiota diversity in development of asthma and atopic disease $(15,30,54)$.

Our data strongly suggest that changes in the intestinal microbiota are sufficient to alter the immune response to a pulmonary viral infection. This alteration led to increased production of inflammatory cytokines with markedly increased mortality. Our data suggest that during homeostasis, intestinal microbiota condition the respiratory immune system so that during a viral infection production of pro-inflammatory cytokines, like IFN $\gamma$, is regulated. With the response regulated, mice survive. However, alteration of the intestinal microbiota reduces the regulatory oversight, allowing for increased IFN $\gamma$ production, leading to increased mortality from the infection.

There are some caveats to our study. First, while streptomycin is thought to be a non-absorbed antibiotic, it is still possible that some of the antibiotic did reach the lung. However, any amount that reached the lung was too small to significantly alter the lung microbiota. Furthermore, it is important to note even with this lack of a significant change in lung microbiota it is still possible that minor effects on lung microbiota could have affected the outcome of our studies.

Our antibody depletion data showed that a CD4-expressing cell was needed to drive the increased mortality. A prior study demonstrated increased expression of IFN $\gamma$ in lung $\mathrm{CD}^{+}{ }^{+} \mathrm{T}$ cells following influenza virus infection. These effector $\mathrm{T}$ cell were able to migrate to the intestine and modify the gut microbiome (55). However, we did not observe an increase in IFN $\gamma$ in $\mathrm{CD}^{+} \mathrm{T}$ cells from $\mathrm{SeV}$-infected lungs following streptomycin treatment. ILCs, and in particular the
ILC1 and LTi subset, express CD4 and produce IFN $\gamma(47,56,57)$. Therefore, our data support the idea that the $\mathrm{CD} 4^{+}$cells producing IFN $\gamma$ were in fact an ILC subclass of cells. It is worth noting that depletion of CD4 cells would deplete both Tregs and the IFN $\gamma$ producing $\mathrm{Lin}^{-} \mathrm{CD} 4^{+}$cells. We believe the reduction in mortality is due to the fact that in the absence of the IFN $\gamma$-producing cells, the protective effect of the Tregs is unnecessary.

Our findings may be an extension of the concept of pathogen tolerance, which suggests that the severity of host response to infection is more dependent on host fitness than pathogen virulence, and the ability to tolerate specific pathogens is part of a host organism's defense strategy $(58,59)$. While this concept focuses on host-pathogen interactions that induce tolerance, our model suggests that host fitness and tolerance to a viral pathogen infection is driven by intestinal commensal-host interaction. In our model, the gastrointestinal microbiota may interact with the immune system to modulate the pulmonary immune response, preventing an excessive and lethal inflammatory response to $\mathrm{SeV}$. However, once the microbiota is disrupted and microbial diversity reduced, this modulation is lost. This triggers a loss of tolerance for the $\mathrm{SeV}$ infection, resulting in increased mortality.

Humans with the least diverse intestinal microbiota include infants and the elderly (60-62) - these are the same populations that have the highest rate of mortality to another paramyxovirus, RSV (63). However, whether reduced diversity contributes to increased mortality in humans infected with RSV remains to be examined. Interestingly, the orthomyxovirus, influenza, is not associated with an increased rate of mortality in infants (63), and an influenza mouse model showed no mortality effect when mice were treated with a non-absorbable antibiotic (29). This may indicate a differential effect of microbial diversity depending on the specific respiratory viral pathogen, or that alterations in specific microbial communities may be more critical to disease outcome than overall microbial diversity.

Recent evidence suggests that the use of antibiotics with different spectra of activity result in very different lung immune responses to influenza virus. For example, treatment with neomycin, a non-absorbable antibiotic, led to a modest decrease in viral clearance without any effect on mortality in a mouse model of influenza infection (29), whereas another report demonstrated that treatment with a cocktail of five antibiotics (ampicillin, gentamicin, metronidazole, neomycin, and vancomycin) not only reduced influenza virus clearance but also led to increased mortality to the virus (64). While the immune responses to influenza and paramyxoviruses (such as $\mathrm{SeV}$ and RSV) may well be disparate, it is also likely that the effects of the distinctive antibiotics on the intestinal microbiota were different. With the use of both absorbable and non-absorbable antibiotics, alterations in lung microbiota also could contribute to differences in host immune response. Our study used only streptomycin, a non-absorbable antibiotic that altered the intestinal microbiota without significantly affecting the lung microbiota, strongly supporting our conclusion that the host pulmonary immune response was being modulated by intestinal commensal-host interactions. While we cannot absolutely rule out any unknown direct toxic effect of the streptomycin, no known signs of streptomycin toxicity were observed in any of the mice. Furthermore, the doses used 
in this study were well below described toxic concentrations of streptomycin in mice (65).

The effect of streptomycin, albeit limited to the gastrointestinal tract, was broad, reducing both diversity and total bacterial burden. While this antibiotic, like other aminoglycosides, is most effective against aerobic bacteria, it still has effects against facultative and obligate anaerobes, as are found in the gastrointestinal tract and is commonly used to disrupt the gastrointestinal microbial ecology. It is important to note that changes seen in the intestinal microbiota may not directly reflect susceptibility to streptomycin, as disruption of gastrointestinal bacterial species often leads to complex outcomes due to alterations in bacterial-bacterial and bacterial-host interactions. Because of the broad changes in microbial composition, demonstrated by $16 \mathrm{~S}$ sequencing, we were unable to identify any specific individual bacterial species that appeared responsible for the altered viral immune response. However, our studies demonstrate significantly decreased abundance of the EREC (Clostridium) bacterial group by qPCR. To the best of our knowledge, this is the first study linking reduction in lung Tregs to dysbiosis of gut microbiome; however, other reports have indicated that treatment with streptomycin can alter the pulmonary T-cell profile (66). Furthermore, effects of targeting indigenous bacterial species in the gut and colon is consistent with previously reported associations between Clostridium clusters IV, XIVa, and XVIII and Treg induction $(7,67,68)$. Future studies will be needed to identify and characterize specific bacterial-bacterial and bacterial-host interactions in the intestinal tract that may be responsible for these immunologic outcomes.

Antibiotic disruption of the intestinal microbiota imparts a marked change on the pulmonary immune response to a respiratory paramyxoviral infection, as manifested by our work. While these data clearly show a role for IFN $\gamma$ in the mortality to an otherwise nonlethal viral infection, the direct contribution of Tregs is less clear. The reduction in mortality with Treg transfer could be due to the Tregs, but very possibly could be through mechanisms not directly related to their regulatory functions. This was something that our current study does not address. It is also worth noting that although currently there is no study showing direct migration of Tregs from gut to lung, there is evidence that short chain fatty acids (acetates) from the gut could regulate Tregs in the lungs $(69,70)$. These data highlight the connection between the intestinal microbiota and the pulmonary immune system and raise concerns over the potential risk of indiscriminate antibiotic use. While the overall impact of these findings on disease awaits further studies, we have begun to examine more fully the bacterial species involved in this response and the specific components of the pulmonary and intestinal immune systems that are most responsive to the microbiota. Clearly the intestinal microbiota plays a significant role in the immune response to pathogens at distant mucosal surfaces. Future studies will continue to provide insight into the importance of these symbionts to health and disease.

\section{REFERENCES}

1. Clemente JC, Ursell LK, Parfrey LW, Knight R. The impact of the gut microbiota on human health: an integrative view. Cell (2012) 148(6):1258-70. doi:10.1016/j.cell.2012.01.035

\section{ETHICS STATEMENT}

This study was carried out in accordance with the recommendations of the Institutional Animal Care and Use Committees of the Medical College of Wisconsin and the Research Institute at Nationwide Children's Hospital. The protocol was approved by the Institutional Animal Care and Use Committees of the Medical College of Wisconsin and the Research Institute at Nationwide Children's Hospital.

\section{AUTHOR CONTRIBUTIONS}

MG, LC, S-RH, DC, and NS designed the experiments, analyzed the data, prepared the figures, and wrote and corrected the manuscript. LC, S-RH, SZ, MH, DH, JS, and MR performed the experiments and assisted in analyzing the results. VL analyzed the data, prepared the figures, and corrected the manuscript. All the authors reviewed the results and approved the final version of the manuscript.

\section{ACKNOWLEDGMENTS}

The authors acknowledge Drs. Michael Holtzman and Eugene Agapov for the kind gift of SeV primer and probes, and Drs. Stephen Gauld and John Routes for helpful discussions on this project. Funding by the NIH (AI120655 and HL087778 to MG; AI057757 and GM099526 to NS), the Children's Research Institute of the Children's Hospital of Wisconsin (to MG and NS), and the Research Institute at Nationwide Children's Hospital (to MG).

\section{SUPPLEMENTARY MATERIAL}

The Supplementary Material for this article can be found online at https://www.frontiersin.org/articles/10.3389/fimmu.2018.01587/ full\#supplementary-material.

FIGURE S1 | Gating strategy for flow cytometry. Single cell suspension of lung cells was analyzed by flow cytometry as shown. (A) Macrophages were identified as large side scatter (SSC) cells that were Mac- $3^{+}$, while lymphocytes were identified by their SSC and forward scatter (FSC), and then were evaluated for expression of CD4, CD8, CD3e, NK1.1, and SeV tetramer as shown. (B) Lymphocytes were identified as in panel (A) and then CD4+ lineage cocktail - (Lin-) cells were examined by intracellular flow cytometry for expression of IFN $\gamma$ (compared with isotype control). Representative data shown.

FIGURE S2 | Depletion of NK1.1 and CD4 in mouse lung. (A) Efficiency of NK1.1 depletion. Representative histograms of lung cells stained for NK1.1 (clone 694370) from mice who had received $100 \mu \mathrm{g}$ lgG2a isotype control (clone C1.18.4) or anti-NK1.1 (clone PK136) i.p. 5 days previously. Bar graph shows frequency of NK1.1-expressing cells in the lymphocyte gate with each treatment. Treatment with anti-NK1.1 led to an average of 97\% reduction of NK1.1-expressing cells compared with the lgG control. (B) Similar experiment as in panel (A) but following CD4 depletion (100 $\mu \mathrm{g}$ clone RM4-5 or eBR2a) and stained with anti-CD4 (clone GK1.5) or isotype control (IgG, clone LTF-2). CD4+ lymphocytes were reduced by $98.3 \%$ at day 5 compared with IgG control. ${ }^{*} p<0.05, n=2 /$ treatment.
2. Salzman NH, Hung K, Haribhai D, Chu H, Karlsson-Sjoberg J, Amir E, et al. Enteric defensins are essential regulators of intestinal microbial ecology. Nat Immunol (2010) 11(1):76-83. doi:10.1038/ni.1825

3. Gaboriau-Routhiau V, Rakotobe S, Lecuyer E, Mulder I, Lan A, Bridonneau C, et al. The key role of segmented filamentous bacteria in the coordinated 
maturation of gut helper T cell responses. Immunity (2009) 31(4):677-89. doi:10.1016/j.immuni.2009.08.020

4. Ivanov II, Atarashi K, Manel N, Brodie EL, Shima T, Karaoz U, et al. Induction of intestinal Th17 cells by segmented filamentous bacteria. Cell (2009) 139(3):485-98. doi:10.1016/j.cell.2009.09.033

5. Lee YK, Menezes JS, Umesaki Y, Mazmanian SK. Proinflammatory T-cell responses to gut microbiota promote experimental autoimmune encephalomyelitis. Proc Natl Acad Sci U S A (2011) 108(Suppl 1):4615-22. doi:10.1073/ pnas. 1000082107

6. Wu HJ, Ivanov II, Darce J, Hattori K, Shima T, Umesaki Y, et al. Gut-residing segmented filamentous bacteria drive autoimmune arthritis via T helper 17 cells. Immunity (2010) 32(6):815-27. doi:10.1016/j.immuni.2010.06.001

7. Atarashi K, Tanoue T, Shima T, Imaoka A, Kuwahara T, Momose Y, et al. Induction of colonic regulatory $\mathrm{T}$ cells by indigenous Clostridium species. Science (2011) 331(6015):337-41. doi:10.1126/science.1198469

8. Lathrop SK, Bloom SM, Rao SM, Nutsch K, Lio CW, Santacruz N, et al. Peripheral education of the immune system by colonic commensal microbiota. Nature (2011) 478(7368):250-4. doi:10.1038/nature10434

9. Round JL, Mazmanian SK. Inducible Foxp3+ regulatory T-cell development by a commensal bacterium of the intestinal microbiota. Proc Natl Acad Sci U S A (2010) 107(27):12204-9. doi:10.1073/pnas.0909122107

10. Cadwell K, Patel KK, Maloney NS, Liu TC, Ng AC, Storer CE, et al. Virusplus-susceptibility gene interaction determines Crohn's disease gene Atg16L1 phenotypes in intestine. Cell (2010) 141(7):1135-45. doi:10.1016/j.cell. 2010.05.009

11. Wen L, Ley RE, Volchkov PY, Stranges PB, Avanesyan L, Stonebraker AC, et al. Innate immunity and intestinal microbiota in the development of type 1 diabetes. Nature (2008) 455(7216):1109-13. doi:10.1038/nature07336

12. Turnbaugh PJ, Ley RE, Mahowald MA, Magrini V, Mardis ER, Gordon JI. An obesity-associated gut microbiome with increased capacity for energy harvest. Nature (2006) 444(7122):1027-31. doi:10.1038/nature05414

13. Mai V, Young CM, Ukhanova M, Wang X, Sun Y, Casella G, et al. Fecal microbiota in premature infants prior to necrotizing enterocolitis. PLoS One (2011) 6(6):e20647. doi:10.1371/journal.pone.0020647

14. de la Cochetiere MF, Piloquet H, des Robert C, Darmaun D, Galmiche JP, Roze JC. Early intestinal bacterial colonization and necrotizing enterocolitis in premature infants: the putative role of Clostridium. Pediatr Res (2004) 56(3):366-70. doi:10.1203/01.PDR.0000134251.45878.D5

15. Blaser MJ. Equilibria of humans and our indigenous microbiota affecting asthma.ProcAm ThoracSoc (2012) 9(2):69-71.doi:10.1513/pats.201108-048MS

16. Penders J, Stobberingh EE, van den Brandt PA, Thijs C. The role of the intestinal microbiota in the development of atopic disorders. Allergy (2007) 62(11):1223-36. doi:10.1111/j.1398-9995.2007.01462.x

17. Russell SL, Gold MJ, Hartmann M, Willing BP, Thorson L, Wlodarska M, et al. Early life antibiotic-driven changes in microbiota enhance susceptibility to allergic asthma. EMBO Rep (2012) 13(5):440-7. doi:10.1038/embor.2012.32

18. Herbst T, Sichelstiel A, Schar C, Yadava K, Burki K, Cahenzli J, et al. Dysregulation of allergic airway inflammation in the absence of microbial colonization. Am J Respir Crit Care Med (2011) 184(2):198-205. doi:10.1164/ rccm.201010-1574OC

19. Croswell A, Amir E, Teggatz P, Barman M, Salzman NH. Prolonged impact of antibiotics on intestinal microbial ecology and susceptibility to enteric Salmonella infection. Infect Immun (2009) 77(7):2741-53. doi:10.1128/IAI. 00006-09

20. Dethlefsen L, McFall-Ngai M, Relman DA. An ecological and evolutionary perspective on human-microbe mutualism and disease. Nature (2007) 449(7164):811-8. doi:10.1038/nature06245

21. Bohnhoff M, Miller CP. Enhanced susceptibility to Salmonella infection in streptomycin-treated mice. J Infect Dis (1962) 111:117-27. doi:10.1093/ infdis/111.2.117

22. Wells CL, Jechorek RP, Erlandsen SL. Evidence for the translocation of Enterococcus faecalis across the mouse intestinal tract. J Infect Dis (1990) 162(1):82-90. doi:10.1093/infdis/162.1.82

23. Wells CL, Maddaus MA, Reynolds CM, Jechorek RP, Simmons RL. Role of anaerobic flora in the translocation of aerobic and facultatively anaerobic intestinal bacteria. Infect Immun (1987) 55(11):2689-94.

24. Bartlett JG, Moon N, Chang TW, Taylor N, Onderdonk AB. Role of Clostridium difficile in antibiotic-associated pseudomembranous colitis. Gastroenterology (1978) 75(5):778-82.
25. Kelly CP, LaMont JT. Clostridium difficile infection. Annu Rev Med (1998) 49:375-90. doi:10.1146/annurev.med.49.1.375

26. Donskey CJ, Chowdhry TK, Hecker MT, Hoyen CK, Hanrahan JA, Hujer AM, et al. Effect of antibiotic therapy on the density of vancomycin-resistant enterococci in the stool of colonized patients. N Engl J Med (2000) 343(26): 1925-32. doi:10.1056/NEJM200012283432604

27. Brandt LJ. American Journal of Gastroenterology Lecture: intestinal microbiota and the role of fecal microbiota transplant (FMT) in treatment of C. difficile infection. Am J Gastroenterol (2013) 108(2):177-85. doi:10.1038/ ajg. 2012.450

28. Kelly CR, Khoruts A, Staley C, Sadowsky MJ, Abd M, Alani M, et al. Effect of fecal microbiota transplantation on recurrence in multiply recurrent Clostridium difficile infection: a randomized trial. Ann Intern Med (2016) 165(9):609-16. doi:10.7326/M16-0271

29. Ichinohe T, Pang IK, Kumamoto Y, Peaper DR, Ho JH, Murray TS, et al. Microbiota regulates immune defense against respiratory tract influenza A virus infection. Proc Natl Acad Sci U S A (2011) 108(13):5354-9. doi:10.1073/ pnas. 1019378108

30. Fujimura KE, Demoor T, Rauch M, Faruqi AA, Jang S, Johnson CC, et al. House dust exposure mediates gut microbiome Lactobacillus enrichment and airway immune defense against allergens and virus infection. Proc Natl Acad Sci U S A (2014) 111(2):805-10. doi:10.1073/pnas.1310750111

31. Grayson MH, Cheung D, Rohlfing MM, Kitchens R, Spiegel DE, Tucker J, et al. Induction of high-affinity IgE receptor on lung dendritic cells during viral infection leads to mucous cell metaplasia. J Exp Med (2007) 204(11):2759-69. doi:10.1084/jem.20070360

32. Cheung DS, Ehlenbach SJ, Kitchens RT, Riley DA, Thomas LL, Holtzman MJ, et al. Cutting edge: CD49d+ neutrophils induce FcepsilonRI expression on lung dendritic cells in a mouse model of postviral asthma. J Immunol (2010) 185(9):4983-7. doi:10.4049/jimmunol.1002456

33. Walter MJ, Morton JD, Kajiwara N, Agapov E, Holtzman MJ. Viral induction of a chronic asthma phenotype and genetic segregation from the acute response. J Clin Invest (2002) 110(2):165-75. doi:10.1172/JCI0214345

34. Cheung DS, Sigua JA, Simpson PM, Yan K, Hussain SA, Santoro JL, et al. Cysteinyl leukotriene receptor 1 expression identifies a subset of neutrophils during the antiviral response that contributes to postviral atopic airway disease. J Allergy Clin Immunol (2017). doi:10.1016/j.jaci.2017.11.026

35. Flynn KJ, Belz GT, Altman JD, Ahmed R, Woodland DL, Doherty PC. Virus-specific CD8+ T cells in primary and secondary influenza pneumonia. Immunity (1998) 8(6):683-91. doi:10.1016/S1074-7613(00)80573-7

36. Caporaso JG, Lauber CL, Walters WA, Berg-Lyons D, Huntley J, Fierer N, et al. Ultra-high-throughput microbial community analysis on the Illumina HiSeq and MiSeq platforms. ISME J (2012) 6(8):1621-4. doi:10.1038/ismej. 2012.8

37. Langmead B, Salzberg SL. Fast gapped-read alignment with Bowtie 2. Nat Methods (2012) 9(4):357-9. doi:10.1038/nmeth.1923

38. Edgar RC. UPARSE: highly accurate OTU sequences from microbial amplicon reads. Nat Methods (2013) 10(10):996-8. doi:10.1038/nmeth.2604

39. Caporaso JG, Kuczynski J, Stombaugh J, Bittinger K, Bushman FD, Costello EK, et al. QIIME allows analysis of high-throughput community sequencing data. Nat Methods (2010) 7(5):335-6. doi:10.1038/nmeth.f.303

40. Quast C, Pruesse E, Yilmaz P, Gerken J, Schweer T, Yarza P, et al. The SILVA ribosomal RNA gene database project: improved data processing and webbased tools. Nucleic Acids Res (2013) 41(Database issue):D590-6. doi:10.1093/ nar/gks1219

41. Oksanen J, Guillaume Blanchet F, Kindt R, Legendre P, Minchin PR, O'Hara RB, et al. vegan: Community Ecology Package. R Package. 2.0-10. CRAN. (2013). Available from: http://vegan.r-forge.r-project.org (Accessed: June 16, 2015).

42. Goslee SC, Urban DL. The ecodist package for dissimilarity-based analysis of ecological data. J Stat Softw (2007) 22(7):1-19. doi:10.18637/jss. v022.i07

43. R Development Core Team. R: A Language and Environment for Statistical Computing Vienna, Austria: R Foundation for Statistical Computing. (2013). [cited 2015]. Available from: http://www.R-project.org (Accessed: June 16, 2015).

44. McArdle BH, Anderson MJ. Fitting multivariate models to community data: a comment on distance-based redundancy analysis. Ecology (2001) 82:290-7. doi:10.1890/0012-9658(2001)082[0290:FMMTCD]2.0.CO;2 
45. Rutstein DD, Stebbins RB, Cathcart RT, Harvey RM. The absorption and excretion of streptomycin in human chronic typhoid carriers. J Clin Invest (1945) 24(6):898-909. doi:10.1172/JCI101677

46. Jordan MB, Hildeman D, Kappler J, Marrack P. An animal model of hemophagocytic lymphohistiocytosis (HLH): CD8+ T cells and interferon gamma are essential for the disorder. Blood (2004) 104(3):735-43. doi:10.1182/ blood-2003-10-3413

47. Monticelli LA, Sonnenberg GF, Abt MC, Alenghat T, Ziegler CG, Doering TA, et al. Innate lymphoid cells promote lung-tissue homeostasis after infection with influenza virus. Nat Immunol (2011) 12(11):1045-54. doi:10.1031/ ni. 2131

48. Abt MC, Lewis BB, Caballero S, Xiong H, Carter RA, Susac B, et al. Innate immune defenses mediated by two ILC subsets are critical for protection against acute Clostridium difficile infection. Cell Host Microbe (2015) 18(1):27-37. doi:10.1016/j.chom.2015.06.011

49. Mock JR, Garibaldi BT, Aggarwal NR, Jenkins J, Limjunyawong N, Singer BD, et al. Foxp3+ regulatory T cells promote lung epithelial proliferation. Mucosal Immunol (2014) 7(6):1440-51. doi:10.1038/mi.2014.33

50. Haribhai D, Williams JB, Jia S, Nickerson D, Schmitt EG, Edwards B, et al. A requisite role for induced regulatory $\mathrm{T}$ cells in tolerance based on expanding antigen receptor diversity. Immunity (2011) 35(1):109-22. doi:10.1016/j. immuni.2011.03.029

51. D’Alessio FR, Tsushima K, Aggarwal NR, West EE, Willett MH, Britos MF, et al. CD4+CD25+Foxp3+ Tregs resolve experimental lung injury in mice and are present in humans with acute lung injury. J Clin Invest (2009) 119(10): 2898-913. doi:10.1172/JCI36498

52. Ivanov II, Frutos Rde L, Manel N, Yoshinaga K, Rifkin DB, Sartor RB, et al. Specific microbiota direct the differentiation of IL-17-producing T-helper cells in the mucosa of the small intestine. Cell Host Microbe (2008) 4(4):337-49. doi:10.1016/j.chom.2008.09.009

53. Henao-Mejia J, Elinav E, Jin C, Hao L, Mehal WZ, Strowig T, et al. Inflammasome-mediated dysbiosis regulates progression of NAFLD and obesity. Nature (2012) 482(7384):179-85. doi:10.1038/nature10809

54. Turturice BA, McGee HS, Oliver B, Baraket M, Nguyen BT, Ascoli C, et al. Atopic asthmatic immune phenotypes associated with airway microbiota and airway obstruction. PLoS One (2017) 12(10):e0184566. doi:10.1371/journal. pone.0184566

55. Wang J, Li F, Wei H, Lian ZX, Sun R, Tian Z. Respiratory influenza virus infection induces intestinal immune injury via microbiota-mediated Th17 celldependent inflammation. J Exp Med (2014) 211(12):2397-410. doi:10.1084/ jem.20140625

56. Crellin NK, Trifari S, Kaplan CD, Cupedo T, Spits H. Human NKp44+IL-22+ cells and LTi-like cells constitute a stable RORC+ lineage distinct from conventional natural killer cells. J Exp Med (2010) 207(2):281-90. doi:10.1084/ jem.20091509

57. Roan F, Stoklasek TA, Whalen E, Molitor JA, Bluestone JA, Buckner JH, et al. CD4+ group 1 innate lymphoid cells (ILC) form a functionally distinct ILC subset that is increased in systemic sclerosis. J Immunol (2016) 196(5):2051-62. doi:10.4049/jimmunol.1600364

58. Medzhitov R, Schneider DS, Soares MP. Disease tolerance as a defense strategy. Science (2012) 335(6071):936-41. doi:10.1126/science.1214935
59. Ayres JS, Schneider DS. Tolerance of infections. Annu Rev Immunol (2012) 30:271-94. doi:10.1146/annurev-immunol-020711-075030

60. Dominguez-Bello MG, Blaser MJ, Ley RE, Knight R. Development of the human gastrointestinal microbiota and insights from high-throughput sequencing. Gastroenterology (2011) 140(6):1713-9. doi:10.1053/j.gastro.2011.02.011

61. Ringel-Kulka T, Cheng J, Ringel Y, Salojarvi J, Carroll I, Palva A, et al. Intestinal microbiota in healthy U.S. young children and adults - a high throughput microarray analysis. PLoS One (2013) 8(5):e64315. doi:10.1371/journal.pone. 0064315

62. Biagi E, Nylund L, Candela M, Ostan R, Bucci L, Pini E, et al. Through ageing, and beyond: gut microbiota and inflammatory status in seniors and centenarians. PLoS One (2010) 5(5):e10667. doi:10.1371/journal.pone.0010667

63. Thompson WW, Shay DK, Weintraub E, Brammer L, Cox N, Anderson LJ, et al. Mortality associated with influenza and respiratory syncytial virus in the United States. JAMA (2003) 289(2):179-86. doi:10.1001/jama.289.2.179

64. Abt MC, Osborne LC, Monticelli LA, Doering TA, Alenghat T, Sonnenberg GF, et al. Commensal bacteria calibrate the activation threshold of innate antiviral immunity. Immunity (2012) 37(1):158-70. doi:10.1016/j.immuni.2012.04.011

65. Bacharach AL, Clark BJ, Mc CM, Tomich EG. Comparative toxicity studies on ten antibiotics in current use. J Pharm Pharmacol (1959) 11:737-41. doi:10.1111/j.2042-7158.1959.tb12620.x

66. Bazett M, Bergeron ME, Haston CK. Streptomycin treatment alters the intestinal microbiome, pulmonary $\mathrm{T}$ cell profile and airway hyperresponsiveness in a cystic fibrosis mouse model. Sci Rep (2016) 6:19189. doi:10.1038/ srep19189

67. Atarashi K, Tanoue T, Oshima K, Suda W, Nagano Y, Nishikawa H, et al. Treg induction by a rationally selected mixture of Clostridia strains from the human microbiota. Nature (2013) 500(7461):232-6. doi:10.1038/nature12331

68. Furusawa Y, Obata Y, Fukuda S, Endo TA, Nakato G, Takahashi D, et al. Commensal microbe-derived butyrate induces the differentiation of colonic regulatory T cells. Nature (2013) 504(7480):446-50. doi:10.1038/nature12721

69. McAleer JP, Kolls JK. Contributions of the intestinal microbiome in lung immunity. Eur J Immunol (2018) 48(1):39-49. doi:10.1002/eji.201646721

70. Thorburn AN, McKenzie CI, Shen S, Stanley D, Macia L, Mason LJ, et al. Evidence that asthma is a developmental origin disease influenced by maternal diet and bacterial metabolites. Nat Commun (2015) 6:7320. doi:10.1038/ ncomms 8320

Conflict of Interest Statement: MG has received research support from Polyphor. The remaining authors declare that the research was conducted in the absence of any commercial or financial relationships that could be construed as a potential conflict of interest.

The reviewer SR and handling Editor declared their shared affiliation.

Copyright (c) 2018 Grayson, Camarda, Hussain, Zemple, Hayward, Lam, Hunter, Santoro, Rohlfing, Cheung and Salzman. This is an open-access article distributed under the terms of the Creative Commons Attribution License (CC BY). The use, distribution or reproduction in other forums is permitted, provided the original author(s) and the copyright owner(s) are credited and that the original publication in this journal is cited, in accordance with accepted academic practice. No use, distribution or reproduction is permitted which does not comply with these terms. 